\title{
Bee SAFE, a Skill-Building Intervention to Enhance CAM Health Literacy: Lessons Learned
}

\section{Authors: Jean Shreffler-Grant, Elizabeth G. Nichols, and Clarann Weinert}

This is a postprint of an article that originally appeared in Health Promotion Practice April 5, 2017. https://dx.doi.org/10.1177/1524839917700612

Shreffler-Grant, Jean, Elizabeth G. Nichols, and Clarann Weinert. "Bee SAFE, a Skill-Building Intervention to Enhance CAM Health Literacy: Lessons Learned." Health Promotion Practice (April 5, 2017). DOI: 10.1177/1524839917700612.

Made available through Montana State University's $\underline{\text { ScholarWorks }}$ 


\title{
Bee SAFE, a Skill-Building Intervention to Enhance CAM Health Literacy: Lessons Learned
}

\author{
Jean Shreffler-Grant, $\mathrm{PhD}, \mathrm{RN}^{1}$ \\ Elizabeth G. Nichols, DNS, RN, FAAN ${ }^{2}$ \\ Clarann Weinert, $\mathrm{PhD}, \mathrm{RN}, \mathrm{FAAN}^{2}$ \\ ${ }^{1}$ Montana State University, Missoula, MT, USA \\ ${ }^{2}$ Montana State University, Bozeman, MT, USA
}

The purpose is to describe a feasibility study of a skillbuilding intervention to enhance health literacy about complementary and alternative (CAM) therapies among older rural adults and share lessons learned. A study was designed to examine the feasibility of an intervention to enhance CAM health literacy. The theme was "Bee SAFE" for Be a wise user of CAM, Safety, Amount, From where, and Effect. Modules were presented face to face and by webinar with older adults at a senior center in one small rural community. The team achieved its purpose of designing, implementing, and evaluating the intervention and assessing if it could be implemented in a rural community. The implementation challenges encountered and lessons learn are discussed. By improving CAM health literacy, older rural adults with chronic health conditions can make wellreasoned decisions about using CAM for health promotion and illness management. The goal is to implement the Bee SAFE intervention in other rural communities; thus team members were attentive to lessons to be learned before investing time, effort, and expense in the larger intervention. It is hoped that the lessons learned can be instructive to others planning projects in rural communities.
$\mathrm{D}$ elivering programs or conducting research in rural communities offers the health professional a number of significant challenges. This is particularly true if the programs involve multiple sessions and if communities are small and isolated. The purpose of this article is to (a) describe a feasibility study of a skill-building intervention to enhance health literacy related to complementary and alternative (CAM) therapies among older rural adults and (b) share the lessons learned while implementing the program in a small rural community. This purpose is consistent with the mission of Health Promotion Practice of research to practice links.

\section{BACKGROUND}

CAM therapies have become an integral component of U.S. health care with nearly $40 \%$ of adults using some form of CAM in their regular care practices for health promotion or treatment of health problems (Barnes, Bloom, \& Nahin, 2008). Adults with chronic health problems, many of whom are older, are significantly more likely to use CAM than those without 
chronic problems (Centers for Disease Control and Prevention, 2016a). The Institute of Medicine (IOM; 2995a) noted the limited quality of CAM information sources used by consumers, as well as the significant proportion of unsupervised or self-care CAM.

Natural products such as herbs and supplements are the most commonly used type of CAM and are readily available for purchase without prescription. Some natural products have potential therapeutic value and so provide viable care options. Others, however, may present health risks if used without an adequate understanding of dose, expected results, known side effects, and potential interactions with medications and/or foods. King and Pettigrew (2004) found that $80 \%$ of the older participants reported using two or more CAM therapies although their self-rated knowledge about the therapies was very low. The IOM (2005a) expressed concern regarding the sources of information about CAM that consumers use and how they evaluate and use the information they have.

Without adequate CAM health literacy or the "information about CAM needed to make informed self-management decisions regarding health" (Shreffler-Grant, Nichols, Weinert, \& Ide, 2013), CAM users may not understand and accurately evaluate all the choices that confront them. Falling victim to fraudulent practices or ingesting potentially harmful substances are serious consequences.

Health literacy is defined as "the degree to which individuals have the capacity to obtain, communicate, process, and understand basic health information and services needed to make appropriate health decisions" (Patient Protection and Affordable Care Act of 2010). Poor health literacy is associated with a variety of adverse health outcomes including increased risk for and prevalence of disease and disability; fewer skills in self-management of health, and more medical and medication treatment errors (Baker et al., 2002; Berkman et al., 2004; Gazmararian, Williams, Peel, \& Baker, 2003; Mancuso, 2009; Weiss \& Palmer, 2004). Individuals with limited literacy have fewer skills to negotiate the complex health care system, resulting in less health care access and increased health care use but less use of preventive care (Nielson-Bohlman, Panzer, \& Kindig, 2004). The elderly are at particular risk. Adults age 65 years and over were found to have lower health literacy scores than adults in any other age-group (Kutner, Greenburg, Jin, \& Paulsen, 2006).

Health disparities among rural residents have long been documented (Gamm, Hutchison, Bellamy, \& Dabney, 2002; Hartley, 2004, IOM, 2005b). Rural residents tend to be older, poorer, and less educated and have more chronic conditions than urban residents, which are characteristics associated with limited health literacy. Zahnd, Scaife, and Francis (2009) found that rural populations had significantly lower literacy levels than urban counterparts.

Based on a series of studies on use of CAM among older rural adults, it was obvious that there was an urgent need to promote health literacy about CAM (Shreffler-Grant et al., 2013; Shreffler-Grant, Hill, Weinert, Nichols, \& Ide, 2007; Shreffler-Grant, Weinert, \& Nichols, 2014; Shreffler-Grant, Weinert, Nichols, \& Ide, 2005). The independent nature of rural dwellers, scarcity of rural health care resources, prevalence of chronic health conditions among older rural adults, a general lack of knowledge about CAM, and concern with the quality of available information about CAM make it critical that older rural consumers have sufficient health literacy about CAM.

The study described in this article took place in a large rural state in the western United States in which nearly all the counties are classified as rural or frontier and most are designated as medically underserved. Most $(80 \%)$ communities are small rural towns with populations of 2,000 or less (U.S. Census, 2013). Adults aged 65 years and older currently account for $16.1 \%$ of the state's population placing the state in the top five states in the United States in percentage of older adults (Montana Department of Public Health and Human Services, 2015; U.S. Census, 2013).

\section{THEORETICAL FRAMEWORK}

The theoretical foundation for this study was the Montana State University (MSU) conceptual model of CAM health literacy (Shreffler-Grant et al., 2013). According to the model, to be CAM health-literate about natural products, individuals need to have knowledge about four major concepts: dose, effect, safety, and availability. Antecedents, the characteristics that the individual brings to the task, have an effect on CAM health literacy. Antecedents in this model are environment, information-seeking propensity, health/ illness trajectory, and general health literacy. The construct, informed self-management of health, is the overall outcome of CAM health literacy. Those who are more CAM health-literate will be more informed selfmanagers of their health. The modules developed for this study focused on the concepts important to CAM health literacy. The MSU conceptual model of CAM health literacy was used to guide the development of the primary outcome measure used to evaluate the intervention, and the four major concepts in the model were addressed in the design of the skill-building session content. In addition, informed self-management of 
health, the outcome of CAM health literacy depicted in the model, was the overriding desired outcome of the skill-building intervention.

\section{METHOD}

\section{Design and Intervention}

A single-site single-group feasibility study with preand posttesting was implemented. The overall project objectives were to (a) develop two skill-building modules, (b) implement the modules to enhance CAM health literacy with a group of older rural dwellers, and (c) evaluate the program. The study was approved by the MSU institutional review board for the protection of human subjects in September 2014.

The content of the skill-building modules was drawn from the literature, the team's experience with prior community-based projects, and existing consumer education resources from federal sources such as the National Network of Libraries of Medicine, MedlinePlus, and the Center for Complementary and Integrative Health website. The content included concepts and skills important for CAM health literacy, communication with providers, and seeking and evaluating health information from electronic sources. Adult learning principles were used and content was geared toward a sixth-grade reading level and consistent with plain language principles. Since the average American adult reads at an eighth-grade level, the IOM (2004) recommended that readability of patient education materials not be higher than sixth- to eighth-grade level. Readability of written materials was evaluated using the Flesch-Kincaid Readability Scale function in Microsoft Word. Plain language principles involve using words that are easy to read, understand, and use while avoiding health care jargon (Centers for Disease Control and Prevention, 2016b).

The intervention was carried out over a 7-week period at a senior center during February and March 2015 and was scheduled to follow the congregate lunch in order to maximize attendance. An initial town hall meeting was held to explain the project, provide basic content on the importance of health literacy and CAM health literacy, and collect Time 1 (T1; prior to program delivery) data. The second session, delivered in a face-to-face format, focused on basic information such as dose, effect, safety, and availability and the importance of communicating with providers. This information is critical for wise and safe use of natural CAM products. At the third session, information regarding skills necessary to seek and evaluate Internet-based materials was presented and delivered
TABLE 1

Summary of Bee SAFE Acronym Used for Skill-Building Intervention

\begin{tabular}{ll}
\hline Bee & Be wise users of CAM products \\
S & Safety: How to decide if the product is safe \\
A & Amount: How much, how often, how long to \\
& take the product \\
F & From where: Where to get it, whether the \\
& Cost is reasonable \\
E & Effect: What the product is intended to do \\
\hline
\end{tabular}

NOTE: CAM = complementary and alternative medicine.

via live webinar. The final session focused on discussion and responses to questions and T2 (after program delivery) data collection and evaluation of the program by the participants. The length for each session including discussion was roughly 1 to $1^{1 / 2}$ hours. Take-home materials were developed to supplement the content.

All study materials followed the Bee SAFE theme selected as a mnemonic device for the content. "Bee SAFE" was intended to serve as a memory jogger to help participants remember the things that are important to think about when taking or considering selfprescribed CAM products. A summary of the Bee SAFE acronym is included in Table 1. In short, the B in Bee SAFE stands for Be wise users of CAM products, $\mathbf{S}$ stands for Safety, A stands for Amount, $\mathbf{F}$ stands for From Where, and $\mathbf{E}$ for Effect. The term Bee Safe was placed on all materials along with a "bumble bee" logo. A bookmark was created as a handout that contained a summary of the Bee SAFE acronym.

\section{Setting, Sample, and Measures}

The site for the study was the senior citizen center in one small rural community. Space for the program at the center consisted of one large multipurpose room. The project grant provided a screen, projector, and computer. The facility had an existing public address system. The participants were men and women 65 years of age and over, who could read and write English, lived in or near the selected community, and were willing to participate.

Data collection measures administered at T1 were as follows: the MSU CAM Health Literacy Scale and two measures of general health literacy, the Newest Vital Sign (Weiss et al., 2005) and the Single-Item Health Literacy measure (Chew, Bradley, \& Boyko, 2004). The MSU CAM Health Literacy Scale is a measure of CAM 
health literacy with 21 items and four response options that was developed and psychometrically evaluated ( $\alpha=.75-.79$ ). A detailed discussion of the development and evaluation of this scale and a copy of the measure are provided in an earlier publication (Shreffler-Grant et al., 2014). A short set of demographic questions was also administered. Measures administered at T2 were the MSU CAM Health Literacy Scale and a set of evaluation questions developed by the team. The evaluation questions included forced-choice items about adequacy of content, delivery mode, length of sessions, as well as open-ended items encouraging written comments. The team also obtained feedback from the senior center director and director of the local Council on Aging about the intervention. Thank-you notes were sent to all participants.

\section{Analysis}

Descriptive statistics were used for analysis of the quantitative results and to identify the frequencies of responses to the evaluation questions. Content analysis was used to identify trends in responses to the qualitative questions. The paired $t$ test was used to examine differences between the MSU CAM Health Literacy Scale scores at $\mathrm{T} 1$ and $\mathrm{T} 2$.

\section{RESULTS}

\section{Feasibility Study}

A total of 17 older adults participated in the full intervention. The mean age was 74.5 years, most were women $(76.5 \%)$, and most were fairly well educated with $64 \%$ having education beyond high school. Sixtyfour percent reported having one or more significant health problem. A majority (73\%) reported having used some form of CAM. The participants were moderately health-literate at baseline with a mean score of $4.18(\alpha$ $=.800$ ) on the Newest Vital Sign (possible range 0-6) and a mean score of 3.64 on the Single-Item Health Literacy measure (possible range $=1-5$ ). The participants also had fairly high levels of CAM health literacy at baseline with a mean score of 70.3 (range of 60-81, $\alpha=.777$ ) on the MSU CAM Health Literacy Scale. The possible range of scores on this scale is 21 to 84 . Although the mean scale scores increased slightly after the intervention $(M=71.47$, range $=60-81, \alpha=.678)$, the change was not statistically significant.

Responses to the evaluation questions revealed that participants found the information on decision making about CAM and communicating with health care providers to be helpful ( $M=4.63$ on 1-5 scale with $1=$ not at all to $5=$ definitely). They reported increased comfort levels in using electronic sources to seek health information ( $M=4.00$ on 1-5 scale). They were satisfied with the scheduling of the program and with the format and content of the face-to-face session but were less satisfied with the webinar session due primarily to technical problems. When asked if they would likely participate if the program was only offered by webinar, the mean was 2.79 on the 1 to 5 scale $(1=$ not at all to $5=$ definitely). Five participants suggested more handouts to accompany the sessions would facilitate retention of the information.

\section{Lessons Learned}

Through this community-based intervention, the team achieved its purpose of conducting and evaluating a feasibility study of a skill-building intervention in a small rural community. Challenges were encountered in the implementation of the study that offered lessons to be learned by the team (see Table 2 for a summary of the lessons learned.)

Gaining Entrée. Gaining entrée to a willing rural community was a challenge. The team members were outsiders to any potential small rural community, and the intervention required time, support, and assistance from people in the community to be successful. For example, the site that was initially recruited suddenly withdrew when the senior center director encountered a family emergency. Another community had to be identified and contacted. Having working relationships with the chief of the state Aging Services Bureau and an extension specialist at the state land grant university helped the team through this challenge. Two other factors assisted with a quick resolution of this challenge: (a) the senior center director in the new community was seeking additional programming for the center and the Bee SAFE intervention fit that need and (b) the center would receive a new computer and media equipment.

Recruitment and Retention. Recruitment and retention of participants in a community-based endeavor are challenges, especially in small rural communities. The center director at the study site was very involved in recruiting participants and was a valuable engaged champion throughout the intervention. She also recruited the director of the local Council on Aging to participate and assist with recruitment.

Anticipating recruitment challenges, several strategies were developed. The sessions were brief in length and occurred immediately after lunch, the natural gathering time for community activities. The dates for the program were selected in conjunction with the center 
TABLE 2

Summary of Lessons Learned in Bee SAFE Intervention

\section{Potential}

Challenges

Potential Solutions

\begin{tabular}{|c|c|}
\hline $\begin{array}{l}\text { Gaining } \\
\text { community entrée }\end{array}$ & $\begin{array}{l}\text { Rural networking } \\
\text { Long term relationship-building }\end{array}$ \\
\hline $\begin{array}{l}\text { Participant } \\
\text { recruitment and } \\
\text { retention }\end{array}$ & $\begin{array}{l}\text { Local media communications } \\
\text { Community-based champion } \\
\text { Community calendar for } \\
\text { planning }\end{array}$ \\
\hline $\begin{array}{l}\text { Local resource } \\
\text { limitations }\end{array}$ & Budget to supplement resources \\
\hline Sustainability & $\begin{array}{l}\text { Local stakeholders involvement } \\
\text { Leave resources at project } \\
\text { completion }\end{array}$ \\
\hline $\begin{array}{l}\text { Understanding } \\
\text { rural culture }\end{array}$ & $\begin{array}{l}\text { Some face-to-face involvement } \\
\text { essential } \\
\text { Supplement face-to-face with } \\
\text { technology } \\
\text { Pretest distance technology in } \\
\text { advance }\end{array}$ \\
\hline $\begin{array}{l}\text { Cost of face-to-face } \\
\text { delivery }\end{array}$ & $\begin{array}{l}\text { Travel time } \\
\text { Budget considerations } \\
\text { Technology support }\end{array}$ \\
\hline Weather & Flexibility in scheduling \\
\hline
\end{tabular}

director to avoid busier times of the year in the community. Still, one session was in conflict with a local church assembly and another with the funeral of a former senior center member. These events affected the number of participants who attended all the sessions and so could be included in the research aspect of the project.

Media activities were conducted to increase the local visibility of the study. Informational posters were created and posted around the town 2 weeks prior to the initial meeting. Announcements were published in the senior center and Council on Aging newsletters. In addition, the local newspaper editor interviewed the team and published an informational article prior to the start date.

Compressing the program schedule (i.e., weekly, rather than biweekly) could mitigate some of the factors that affected attendance; although the qualitative comments revealed that participants were happy with the every-other-week scheduling. Life happenings, illnesses, deaths, and weather conditions cannot be scheduled or avoided, but they do pose challenges to maintaining a research sample. Recording the sessions to facilitate those who could not attend to obtain missed information is an option, although this would add additional confounding variables to the research aspect.

Following the intervention, an electronic file of the skill-building modules was provided for posting on the senior center's website and loaded on the new computer. This allowed additional participants to access the modules over time. Although no planned follow-up evaluation of this strategy occurred, the center director indicated that the electronic file was viewed after the program and that the computer and media equipment was being used for health-related activities.

Cost of On-Site Intervention. The remote locations of many rural communities made face-to-face delivery of content costly in terms of time and travel for the research team. To address this challenge, one skill-building session was delivered by webinar from a distant location. Technical difficulties relating to the software used at the broadcasting site resulted in a session that was difficult for the participants to follow. Fortunately, a member of the research team was on site and able to mitigate some of the problems, but not all. A handout covering the problematic content was developed and distributed at the next (final) session. It was evident that more extensive testing of distance connections and software is necessary. Participants also suggested using larger fonts when electronically delivering content.

Limitations of Local Resources in Facility. Many rural senior citizens centers are located in older repurposed buildings that do not provide ideal presentation settings. This intervention site was a former train depot with a long rectangular multipurpose room with several round tables, less than optimal acoustics, and multiple unshaded windows. The center had a public address system used for bingo games that was not very effective for the intervention presentations. The team had anticipated that presentation equipment might not be available at the participating center and so had budgeted to purchase and donate a computer, screen, speakers, projector, and wireless modem. To support the project, the center director upgraded the Internet connection; however, this may not always be possible. Thus it is important to assess the level of Internet access in the rural community. Installation of the media equipment was another challenge the team had not anticipated. The center director, however, arranged to have a local community service group install the equipment. 
Sustainability. From the outset, the intent was to build community resources to sustain the efforts beyond the grant funded intervention. The involvement and commitment of local stakeholders such as the Center and Council on Aging Directors and the local librarian were cultivated not only to enhance the success of the intervention but also to enable these individuals to serve as ongoing information resources for the seniors. The team met with the senior center director prior to implementation to explain the study and her role, answer questions, and obtain buy-in. The team also met with the local librarian to explain the study, answer questions, and invite her to attend the sessions, since libraries are often used to seek health information.

Donating a computer when the intervention ended was planned to encourage seniors to continue to seek Internet information about CAM and other health issues and to promote the ongoing use of the skillbuilding modules. The projector and screen used in the intervention could be used for additional learning and social opportunities.

\section{DISCUSSION}

Consistent with the purpose of a feasibility study, the authors found that this project is indeed feasible. The challenges and approaches attempted to counter them, however, can be used to guide changes and strategies to strengthen this and similar interventions conducted in small rural communities.

The CAM health literacy level among participants in this study was increased following the intervention, although not significantly. The study was not intended to test the impact of the intervention on CAM health literacy; rather, it was intended to test the feasibility of the approach. The use of a small convenience sample without a comparison group precluded the ability to test the effectiveness of the intervention. The participants had fairly high levels of general and CAM health literacy prior to the intervention. They were also well educated, and education is positively associated with health literacy. The participants reported a higher prevalence of CAM use than that found in national studies (73\% compared to $40 \%$ nationally) and thus may have had more prior knowledge about it. Selection bias may also have been a factor, in that people with an interest in CAM may have been more likely to attend the program. Data collected in this study do not permit identification of what accounted for the lack of significant improvement in CAM health literacy scores, although the small sample was a likely factor. Despite the lack of significant changes in scores, the qualitative data indicated the participants found the program interesting, informative, and useful, and thus the program may lead to more informed self-management decisions about health, which is the intended outcome of CAM health literacy. The team plans ongoing evaluation of the MSU CAM Health Literacy Scale including assessment of validity and reliability, as well as sensitivity to detect changes in scores should they occur following the intervention. The robustness of the skillbuilding intervention to improve CAM health literacy will also be assessed prior to replication.

This research team's long-term goal is to continue the Bee SAFE CAM Health Literacy intervention in other rural communities. As this feasibility study was implemented, the team was attentive to lessons to be learned about what worked and what did not before investing time, effort, and expense in the larger intervention.

\section{CONCLUSIONS}

Health care consumers make many decisions about health care and use a wide variety of self-care health products for health promotion and relief of symptoms; decisions often made independent of their health care providers. This is especially true for older rural adults who engage in more self-care and have less access to allopathic care than urban adults (Shreffler-Grant et al., 2005). Those with chronic health conditions are also more likely to use CAM (Centers for Disease Control and Prevention, 2016a).

Making informed decisions about the use of CAM requires a somewhat sophisticated level of health literacy. Without adequate CAM health literacy, older rural consumers may not know of all the appropriate health care choices that may benefit or harm them. By improving CAM health literacy, older rural adults living with chronic health conditions can make well-reasoned decisions about using CAM for their health promotion and illness management options. It is hoped that the challenges and lessons learned in this study will be instructive to others planning research, service, or educational projects in rural communities.

\section{REFERENCES}

Baker, D. W., Gazmararian, J. A., Williams, M. V., Scott, T., Parker, R. M., Green, D., . . . Peel, J. (2002). Functional health literacy and the risk of hospital admission among Medicare managed care enrollees. American Journal of Public Health, 92, 1278-1283.

Barnes, P., Bloom, B., \& Nahin, R. L. (2008). Complementary and alternative medicine use among adults and children: United States, 2007 (National Health Statistics Report No. 12). Hyattsville, MD: National Center for Health Statistics.

Berkman, N. D., DeWalt, D. A., Pignone, M. P., Sheridan, S. L., Lohr, K. N., Lux, L., . . B Bonito, A. J. (2004). Literacy and health 
outcomes (Evidence Report/Technology Assessment No. 87). Chapel Hill: RTI International-University of North Carolina.

Centers for Disease Control and Prevention. (2016a). Multiple chronic conditions and use of complementary and alternative medicine among US adults: Results from the 2012 National Health Interview Survey (Vol.13). Retrieved from https://www. cdc.gov/pcd/issues/2016/15_0501.htm

Centers for Disease Control and Prevention. (2016b). Plain language materials \& resources. Retrieved from http://www.cdc.gov/ healthliteracy/developmaterials/plainlanguage.html

Chew, L., Bradley, K., \& Boyko, E. (2004). Brief questions to identify patients with inadequate health literacy. Family Medicine, 36, 588-594.

Gamm, L., Hutchison, L., Bellamy, G., \& Dabney, B. J. (2002). Rural healthy people 2010: Identifying rural health priorities and models for practice. Journal of Rural Health, 18, 9-14.

Gazmararian, J. A., Williams, M. V., Peel, J., \& Baker, D. W. (2003). Health literacy and knowledge of chronic illness. Patient Education and Counseling, 51, 267-275.

Hartley, D. (2004). Rural health disparities, population health, and rural culture. American Journal of Public Health, 94, 1675-1678.

Institute of Medicine. (2004). Health literacy: A prescription to end confusion. Washington DC: National Academies Press.

Institute of Medicine. (2005a). Complementary and alternative medicine in the United States. Washington DC: National Academies Press.

Institute of Medicine. (2005b). Quality through collaboration: The future of rural health. Washington DC: National Academies Press.

King, M. O., \& Pettigrew, A. C. (2004). Complementary and alternative therapy use by older adults in three ethnically diverse populations: A pilot study. Geriatric Nursing, 25, 30-37.

Kutner, M., Greenburg, E., Jin, Y., \& Paulsen, C. (2006). The health literacy of American's adults: Results from the 2003 National Assessment of Adult Literacy. Washington, DC: U.S. Department of Education.

Mancuso, J. M. (2009). Assessment and measurement of health literacy: An integrative review of the literature. Nursing $\&$ Health Sciences, 11, 77-89.
Montana Department of Public Health and Human Services. (2015). Montana State Plan on Aging, 2015-2019. Retrieved from https:/dphhs.mt.gov/Portals/85/sltc/documents/AgingReports/ FinalApproved2016-2019STPlanonAging.pdf

Nielson-Bohlman, L., Panzer, A. M., \& Kindig, D. A. (Eds.). (2004). Health literacy: Prescription to end confusion, Washington, DC: National Academies Press.

Patient Protection and Affordable Care Act of 2010. Pub. L. No. 111-148: Title V, Subtitle A, Sec 5002.

Shreffler-Grant, J., Hill, W., Weinert, C., Nichols, E., \& Ide, B. (2007). Complementary therapy and older rural women: Who uses and who does not? Nursing Research, 56, 28-33.

Shreffler-Grant, J., Nichols, E. G., Weinert, C., \& Ide, B. (2013). The Montana State University conceptual model of complementary and alternative medicine (CAM) health literacy. Journal of Health Communication, 18, 1193-1200. doi:10.1080/10810730.30 13.778385

Shreffler-Grant, J., Weinert, C., \& Nichols, R. (2014). Instrument to measure health literacy about complementary and alternative medicine. Journal of Nursing Measurement, 22, 489-499.

Shreffler-Grant, J., Weinert, C., Nichols, E., \& Ide, B. (2005). Complementary therapy use among older rural adults. Public Health Nursing, 22, 323-331.

U.S. Census Bureau. (2013). American factfinder. Retrieved from http://factfinder2.census.gov/faces/tableservices/jsf/pages/ productview.xhtml?pid=DEC_10_113_GCTPH1.ST04\&prodType= table

Weiss, B. D., Mays, M. Z., Martz, W., Castro, K. M., DeWalt, D. A., Pignone, M. P., . . . Hale, F. A. (2005). Quick assessment of literacy in primary care: The newest vital sign. Annals of Family Medicine, 3, 514-522.

Weiss, B. D., \& Palmer, R. (2004). Relationship between health care costs and very low literacy skills in a medically needy and indigent Medicaid population. Journal of the American Board of Family Practice, 17, 44-47.

Zahnd, W. E., Scaife, S. L., \& Francis, M. L. (2009). Health literacy skills in rural and urban populations. American Journal of Health Behavior, 33, 550-557. 